\title{
NARRATIVAS TRANSMEDIA EN LA COMUNICACIÓN DE CATÁSTROFES: EL TERREMOTO DE ECUADOR DEL 2016
}

\author{
JuAn PABlo Arrobo-Agila* \\ Universidad Técnica Particular de Loja \\ jparrobo1@utpl.edu.ec \\ ABEL SUING** \\ Universidad Técnica Particular de Loja \\ arsuing@utpl.edu.ec \\ IGNACIO AGUADED*** \\ Universidad de Huelva \\ aguaded@uhu.es
}

Recibido: 14/6/2021 Aceptado: 20/8/2021

doi: https://doi.org/10.26439/contratexto2021.n036.5230

RESUMEN. La investigación se enfoca en analizar las narrativas transmedia al momento de informar sobre un terremoto desde un medio de comunicación digital nacional y un medio internacional; también se examina el impacto de la red social Facebook al difundir el acontecimiento. El objetivo es comparar el contenido generado a partir del terremoto del 16 de abril del 2016 en Ecuador mediante el uso de herramientas transmedia en los diarios El Comercio (Ecuador) y El País (España), y en la red social Facebook. Se pretende conocer el rol de la audiencia como prosumidores de información. La metodología aplicada fue mixta, cualitativa y cuantitativa; la muestra analizada fue de 1126 piezas informativas del diario El Comercio, 44 del diario El País y 1155 menciones de Facebook. La necesidad de educar e informar a los ciudadanos sobre la prevención de las consecuencias de los desastres naturales y el tratamiento que dan los medios digitales de comunicación justifica el estudio. La importancia de contar con medidas de prevención

\footnotetext{
* Doctor en Comunicación por la Universidad de Huelva, España (véase: https://orcid.org/0000-0002-63152218).

** Doctor en Comunicación por la Universidad de Santiago de Compostela, España (véase: https://orcid. org/0000-0002-4234-5926)

*** Doctor en Psicopedagogía por la Universidad de Huelva, España (véase: https://orcid.org/0000-00020229-1118).
} 
hace de esta investigación un aporte para la ciudadanía. La narrativa periodística se fortalece en la variedad de recursos que permiten retratar una historia en diversos contextos; como se muestra en esta investigación, los recursos más utilizados siguen siendo la fotografía y el video.

PALABRAS CLAVE: desastres naturales / narrativas transmedia / redes sociales / prensa digital / comunicación

\section{TRANSMEDIA NARRATIVES IN COMMUNICATION IN TIMES OF CRISIS: THE 2016 ECUADOR EARTHQUAKE}

ABSTRACT. The research focuses on analyzing transmedia narratives when reporting on an earthquake from a national digital newspaper, an international one, and also the impact of Facebook when disseminating the event. The objective is to compare the content generated about the earthquake of April 16, 2016, in Ecuador through transmedia tools in El Comercio (Ecuador) and El País (Spain), and Facebook. The aim is to know the role of the audience as prosumers of information. The methodology applied was mixed: qualitative and quantitative; the sample analyzed was 1126 informative pieces from $E l$ Comercio, 44 from El País and 1155 Facebook mentions. The need to educate and inform citizens about preventing the consequences of natural disasters and the treatment given by digital media justifies the study. The importance of having prevention measures makes this research a contribution to citizenship. The journalistic narrative is strengthened by various resources that allow portraying a story in different contexts; as shown in this research, the most used resources are still photography and video.

KEYWORDS: natural disasters / transmedia narratives / social networks / digital press / communication 


\section{NARRATIVAS TRANSMÍDIA NA COMUNICAÇÃO DE DESASTRES: 0 TERRAMOTO DE 2016 NO EQUADOR}

RESUMO. A investigação centra-se na análise de narrativas transmídia ao relatar um terramoto num meio digital nacional e internacional, também examina-se o impacto da rede social Facebook ao disseminar o evento. 0 objetivo é comparar o conteúdo gerado pelo terramoto de 16 de Abril de 2016, no Equador, por meio da utilização de ferramentas transmídia nos jornais El Comercio (Equador) e El País (Espanha), e na rede social Facebook. 0 objetivo é compreender o papel do público como prosumidor de informação. A metodologia aplicada foi mista, qualitativa e quantitativa, a amostra analisada foi de 1126 peças de informação do jornal El Comercio, 44 do jornal El País e 1155 menções no Facebook. A necessidade de educar e informar os cidadãos sobre a prevenção das consequências das catástrofes naturais e o tratamento dado pelos meios digitais justifica o estudo. A importância das medidas de prevenção faz desta investigação um aporte para o público. A narrativa jornalística é reforçada pela variedade de recursos que permitem retratar uma história em diferentes contextos, os recursos mais utilizados continuam a ser a fotografia e o vídeo como é demonstrado nesta pesquisa,

PALAVRAS-CHAVE: catástrofes naturais / narrativas transmídia / redes sociais / jornalismo digital / comunicação 


\section{INTRODUCCIÓN}

Los terremotos son fenómenos naturales que se presentan de forma instantánea provocando destrucciones y daños de gran magnitud; esto los convierte en uno de los fenómenos más destructores y temidos. Los efectos en las personas y sus actividades pueden ocurrir de forma directa o indirecta. De forma directa causan muertes, heridos, destrucción de viviendas, de instalaciones públicas e industriales, etcétera. Y de manera indirecta provoca deslizamientos, fuego, inundaciones, tsunamis, epidemias y lo más grave: la ruina económica de una región (Vidal, 1994). El Ecuador fue azotado por un terremoto en el año 2016, que provocó devastación y pérdidas económicas en todo el país, principalmente en las zonas afectadas de las provincias de Manabí y Esmeraldas.

Para tener una idea de la magnitud y fuerza de destrucción de los terremotos, podemos analizar algunas cifras; por ejemplo, el terremoto del 27 de julio de 1976 dejó en China al menos unos 650000 muertos y unos 780000 heridos; el sismo del 19 de septiembre de 1985 en México provocó unos 9500 muertos y unos 300000 heridos; el 15 de agosto del 2007 en el Perú se contabilizaron más de 500 fallecidos tras un terremoto de 8,0 grados; el 12 de enero del 2010 en Haití un terremoto de 7,0 grados dejó cerca de 316000 muertos y 1,6 millones de personas sin hogar; en el mismo año, el 27 de febrero en Chile un terremoto de 8,8 grados dejó 26 muertos; el 11 de marzo del 2011, en Japón, un terremoto de 9 grados y posterior tsunami dejó un saldo de 15880 muertos y 2698 desaparecidos; en Ecuador, el terremoto del 16 de abril del 2016, con una magnitud de 7,8 grados, dejó 671 muertos; y uno de los últimos terremotos, el 19 de septiembre del 2017, en México, dejó cerca de 318 muertos.

La importancia de contar con medidas de prevención hace de esta investigación un aporte para la ciudadanía.

El terremoto en Ecuador ocurrió el 16 de abril del 2016 a las 18:58 horas con una duración de 55 segundos; el epicentro fue entre Muisne, en la provincia de Esmeraldas, Pedernales y Cojimíes, en la provincia de Manabí, con una magnitud de 7,8 grados en la escala de Richter. Ecuador, al ubicarse en el Cinturón de Fuego del Pacífico, está expuesto a movimientos tectónicos producidos por la placa oceánica de Nasca y la placa continental sudamericana.

La relevancia de este estudio es precisar el nivel de cobertura que tuvo este desastre provocado por causas naturales, que ocurrió en un momento de configuración de los medios digitales y las narrativas transmedia, cuando los usuarios tienen la capacidad de construir relatos y complementar los reportes que emiten los medios tradicionales. Hay riesgos y beneficios en las narrativas que construyen los usuarios, por ejemplo, la falta de rigurosidad, la inmediatez y la proximidad a los acontecimientos; sin embargo, es un fenómeno comunicacional que gana vigencia. 
Debe entenderse que la nueva comunicación deja de lado lo tradicional y se lanza a nuevas formas de llegar a las personas; la manera de hacer comunicación ha cambiado, la redacción en los diarios ya no se lleva a cabo desde una oficina o la transmisión de una noticia por televisión, ahora con un teléfono inteligente es suficiente. En este sentido, el usuario se ha convertido en un generador de contenidos.

Jenkins (2007) afirma que hemos entrado en una nueva era de convergencia de medios que vuelve inevitable el flujo de contenidos a través de múltiples canales. Por su parte, Renó (2013) señala que el término narrativas transmedia surgió del concepto de dialogismo y de polifonía de Mijaíl Bajtín, pero el primer uso se atribuye a Stuart Saunders Smith, en 1975, quien afirmó que al juntar fragmentos musicales de ritmos e instrumentos daría una nueva composición que denominó transmedia music (p. 150). Acerca del concepto de narrativas transmedia se ha escrito mucho desde diversas áreas como la sociología, el periodismo, la semiótica, el cine, la filosofía y fundamentalmente desde la comunicación.

Las narrativas transmediáticas son realidades tan complejas que surgen desde distintos factores. El transmedia no es la adaptación de otra creación, sino un modo distinto de crear y de adaptar (Mora, 2014). Por ningún concepto se puede concebir la adaptación de una historia a un nuevo medio como una narrativa, ni mucho menos, sino que simplemente es una de las tantas herramientas.

La evolución tecnológica ha abierto un campo a la transformación de la industria audiovisual: a partir de los noventa y en la primera década del siglo XXI, se vive un proceso de reconversión industrial. Surge así una nueva forma de narración generada para contar historias por medio de numerosas plataformas y formatos (Jenkins, 2009). Las narrativas transmedia se han convertido en un término que da paso a numerosas puntualizaciones (Scolari, 2011). Los espectadores asumen un papel activo en el proceso de expansión de los contenidos (Scolari et al., 2012).

Renó et al. (2014) definen a las narrativas transmedia como "una forma de comunicación contemporánea que actúa a partir de pilares fundamentales; entre ellos, la participación, la interactividad, la circulación de redes sociales y blogosfera, y la movilidad" (p. 54). De esta forma, se da una mayor interactividad, movilidad y participación por parte del autor, que pasa a ser considerado un prosumidor de contenidos.

El concepto de prosumidor ya fue anticipado por Marshall McLuhan y Barrington Nevitt en su libro Take Today (1972), quienes señalaron que la tecnología electrónica iba a permitir al consumidor asumir simultáneamente ambos papeles, el de productor y consumidor de contenidos (como se citó en Islas, 2008). En los años ochenta, Alvin Toffler introdujo el término prosumidor en el libro La tercera ola (1981). Lo señala en el capítulo $X X$, "El surgimiento del prosumidor". Toffler comienza el relato describiendo el aporte que este le da a la "economía invisible": 
Durante la primera ola la mayoría de las personas consumían lo que ellas mismas producían. No eran ni productores ni consumidores en el sentido habitual. Eran, en su lugar, lo que podría denominarse prosumidores. Fue la revolución industrial lo que, al introducir una cuña en la sociedad, separó estas dos funciones y dio nacimiento a lo que ahora llamamos productores y consumidores [...] si examinamos atentamente la cuestión, descubrimos los comienzos de un cambio fundamental en la relación mutua existente entre estos dos sectores o formas de producción. Vemos un progresivo difuminarse de la línea que separa al productor del consumidor. Vemos la creciente importancia del prosumidor. Y, más allá de eso, vemos aproximarse un impresionante cambio que transformará incluso la función del mercado mismo en nuestras vidas y en el sistema mundial. (pp. 176-177)

Es importante asumir el concepto de "la sociedad de riesgo" del alemán Ulrich Beck, quien señala que una sociedad expuesta al peligro inminente amenaza la seguridad misma de la existencia del ser humano. Beck afirma textualmente que "la sociedad del riesgo es la época del industrialismo en la que los hombres han de enfrentarse al desafío que plantea la capacidad de la industria para destruir todo tipo de vida sobre la tierra" (como se citó en Ballesteros, 2014, p. 209). La industrialización de la época moderna y la mano del hombre han marcado la destrucción de la naturaleza misma. La sociedad de riesgo que plantea Beck se aplica en este caso a los efectos que deja un fenómeno como los terremotos, sobre todo cuando ocurren en países del tercer mundo como Ecuador y donde no existen políticas nacionales de prevención que permitan reducir la brecha de diferencias sociales entre los países pobres y ricos.

\section{Cobertura de desastres}

Los estudios sobre catástrofes en los medios de comunicación (Crovi y Lozano, 2010; Francescutti et al., 2013; Lozano y Amaral, 2018; Teso et al., 2018; Lozano y Toussaint, 2019) insisten en el papel de los ciudadanos, en su participación para formar competencias informativas sobre la prevención para disminuir las consecuencias negativas.

En una emergencia la información es el elemento más preciado, "es aquello que todos buscan y necesitan para tomar decisiones, para ganar o perder visibilidad y credibilidad" (Arroyo et al., 2009, p. 16). Una oportuna información permite una rápida y eficaz respuesta. Lozano y Amaral (2018) señalan que las rutinas periodísticas en situaciones de catástrofes imponen sus relatos y construyen socialmente las versiones oficiales de lo ocurrido. Lamentablemente, lo frecuente ha sido que "los medios y las redes sociales, cuando citan grandes catástrofes, no suelen contar que [...] de las decisiones tomadas para mantener nuestras formas de vida, en seguridad y en estabilidad, se encuentran muchas de las 'causas' de esas catástrofes" (Lozano et al., 2020, p. 1184).

Luego de los hechos, los medios digitales y las redes sociales entran en acción, pero las coberturas informativas de catástrofes, por lo general, están más pendientes 
de informar sobre la destrucción que sobre la previsión; prefieren esquemas narrativos de simplificación (Lozano y Amaral, 2018; Souza-Mayerholz y Martínez-Ravanal, 2011).

En algunos países ha sido el gobierno quien solicita a los medios de comunicación mantener informada a la ciudadanía. Los periodistas y demás actores son un ente activo en la planificación de estrategias de gestión de riesgo frente a los desastres naturales; la información que generan los periodistas, así como las entidades autorizadas por el gobierno, sirve para un mejor manejo y planificación de las acciones antes y después de los eventos catastróficos.

Los medios ayudan a afianzar la relación entre la población y las autoridades de gobierno; suman su contingente a las entidades encargadas de enfrentar los daños como “la Secretaría de Gestión de Riesgos, la Cruz Roja Ecuatoriana y el personal sanitario [...] muy importante para la prevención y/o mitigación de desastres naturales" (Abad-Sojos et al., 2018, p. 3).

Internet se ha convertido en la plataforma trascendental debido a su instantaneidad con relación a otros medios. La actualización y constante fluidez de la información permiten que en segundos la población esté enterada de los hechos (Marcelo y Marcelo, 2021). En el caso de Ecuador, las personas se informaron en los primeros instantes por medios como la radio, y principalmente por plataformas digitales como Twitter. "A través de Twitter, el hashtag \#Temblor se convirtió en tendencia en menos de cinco minutos y los usuarios reportaron que se sintió en varias zonas de Guayaquil y Loja", como señaló El Comercio el 16 de abril del 2016. En otros terremotos sucedió igual; el 12 de enero del 2010, en Haití, "todas las líneas telefónicas se colapsaron, internet pasó a ser fundamental y las redes sociales se usaron para la obtención y difusión masiva de información y para transmitir imágenes del suceso" (Manjón, 2020, p. 36).

Cuando se produjo el terremoto de Ecuador, los medios nacionales demoraron más de dos horas para emitir información de lo que acababa de suceder. Suing (2018), citando a Rivera y Rodríguez, señala que los medios de comunicación, en particular la televisión, tuvieron "una reacción tardía frente a la emisión de información. Su justificación se ampara en la Ley Orgánica de Comunicación, que señala que los medios de comunicación verán suprimido su derecho a la libre expresión en casos de emergencia nacional" (p. 376). Pellegrini et al. (2015), en su análisis sobre la cobertura de la televisión chilena con relación al terremoto de ese país en el 2010, manifiestan que los periodistas en este tipo de situaciones están forzados a trabajar bajo fuerte presión, incertidumbre y vulnerabilidad personal.

\section{Desastres a través de las redes sociales}

Las redes sociales son piezas fundamentales para informar y generar comunicación. Toala y Camino (2017), en su investigación sobre las reacciones de los nodos de una red 
social luego del terremoto de Ecuador, señalan que la red social Facebook jugó un papel importante en la difusión de la información.

En los últimos años las redes sociales, principalmente Facebook, Twitter, Instagram y Tuenti, se han convertido en fuentes de información para las audiencias y medios de comunicación. La rápida expansión que tienen entre sus usuarios ha hecho que medios de comunicación las acojan como plataforma de difusión y expansión de información. Para enero del 2016, de acuerdo con los datos de Alcázar (2020), había cerca de un millón seiscientos mil usuarios en Facebook principalmente de Guayaquil y Quito. Para el año 2020, Facebook, en conjunto con sus marcas como Instagram, Messenger y WhatsApp, alcanzó los trece millones de usuarios.

En el terremoto del 2016 en Ecuador, las redes sociales se activaron con rapidez, y Facebook fue una de las más visitadas. De acuerdo con el diario El Comercio de Ecuador, la red social a partir de las 20:00 horas del 16 de abril ofreció una función que permitía a las personas dar a conocer su estado de salud en ese momento. Al igual que Facebook, Twitter jugó un papel relevante; las comunicaciones se empezaron a dar utilizando los hashtags \#DesaparecidosEc y \#EncontradosEc. La plataforma se convirtió en fuente informativa para medios nacionales e internacionales dada la magnitud de información. Este bagaje y utilización de las redes sociales como primeras fuentes de información y espacios para publicar se debió a la expansión de la cobertura digital que ya existía en el país.

\section{Objetivos de la investigación}

Los objetivos de la investigación son los siguientes: (a) comparar las piezas periodísticas publicadas, mediante el uso de las narrativas digitales, en los portales web de los diarios El Comercio (Ecuador) y El País (España), acerca del terremoto ocurrido en Ecuador el 16 de abril del 2016; y (b) analizar la interacción de los prosumidores a través de las publicaciones que realizaron sobre el terremoto entre abril y mayo del 2016 mediante Facebook. Para atender los objetivos propuestos, se plantean las siguientes preguntas de investigación: (1) ¿cuál es la importancia que dan los medios digitales a la cobertura de un fenómeno natural en un contexto nacional e internacional?; y (2) ¿qué nivel de alcance tienen las redes sociales a través del papel de los usuarios en calidad de prosumidores al momento de informar sobre un desastre natural?

\section{METODOLOGÍA}

La investigación es exploratoria y de carácter descriptivo. El estudio se define a través de variables de medición, análisis estadístico y de datos. Es decir, con un enfoque cuantitativo y cualitativo se realiza un estudio de validación de las herramientas aplicadas 
para la obtención de la información, se analiza la cantidad de piezas periodísticas que se publicaron en el diario El Comercio de Ecuador y El País de España durante el primer mes después del terremoto del 16 de abril del 2016. El rango de estudio es del 16 de abril al 16 de mayo del 2016. Asimismo, se analiza la cantidad de publicaciones con relación al terremoto que se dieron en las mismas fechas usando la plataforma de Facebook.

La relevancia de analizar el diario El Comercio de Ecuador surge por la necesidad de conocer la cobertura que realiza a nivel nacional sobre lo acontecido en el país, dado que es uno de los medios con mayor influencia en la utilización de herramientas digitales y nuevas narrativas en el periodismo. Rivera (2020) señala en una de sus investigaciones sobre el periodismo de datos en Ecuador que el diario El Comercio, por su trayectoria de décadas de fundación, cuenta con una mayor audiencia digital, debido a que este medio se ha adaptado al nuevo formato.

El diario El Comercio con su sección para datos e investigación que lleva por nombre "El Comercio Data" lidera esta tendencia en el país; en sus espacios han interpretado y puesto bases de datos para servicios y consultas de los usuarios. (Rivera, 2020, p. 8)

Lo mismo indica la plataforma Mentinno en su ranking digital sobre medios de comunicación en Ecuador del año 2019: entre los diez medios digitales más visitados en el mes, el diario El Comercio se sitúa en el primer lugar con 10,9 millones de visitas mensuales (Alcázar, 2020). Por otro lado, surge la necesidad de analizar el diario El País de España para conocer a nivel internacional la cobertura que dieron al terremoto y cómo este afectó a la comunidad migrante que reside en el país ibérico. Se consideró este medio español por ser uno de los medios más leídos; de acuerdo con elDiario.es de España, entre los medios más leídos están El País, luego El Mundo y 20 Minutos ("elDiario. es, el cuarto periódico digital más leído y el que más crece", 2020), con un porcentaje de lectura en el medio digital del $26,1 \%$. Finalmente, se justifica el análisis de la red social Facebook por la necesidad de conocer la participación de la comunidad nacional e internacional desde el mismo instante que ocurrió el fenómeno natural; de esta manera, se decidió analizar esta plataforma por la accesibilidad a la información y datos recabados con relación al terremoto.

El análisis compara las cantidades de piezas periodísticas después del terremoto con el fin de establecer la participación de las personas en la manera de informar, para así determinar la influencia que estos tuvieron, el modo de comunicarse, el lenguaje utilizado, horas y días de mayor publicación, además de los diferentes patrones de comunicación.

Una vez desarrollado el instrumento de análisis para medir la información sobre el terremoto, se procedió a realizar una selección de expertos para validarlo; el comité estuvo integrado por seis expertos relacionados con la comunicación, el periodismo y 
la investigación, que proceden de España, Ecuador y Perú, y laboran en universidades de alto prestigio. Para la elaboración del instrumento se consideraron los aportes de Mendoza-Michilot (2017), de la Universidad de Lima, y de Pellegrini et al. (2011), de la Universidad Católica de Chile, quienes proponen el valor agregado periodístico (VAP). La importancia de la utilización de este tipo de metodología, y del instrumento de análisis, radica en que ya han sido aplicados en trabajos de análisis de la calidad periodística de medios latinoamericanos, así como de la calidad de la información difundida acerca de un terremoto por parte de la televisión chilena, en los estudios realizados por la profesora Silvia Pellegrini, de la Universidad Católica de Chile.

A continuación, se presenta la ficha final con la que se empezaría a realizar el análisis de la información recogida de los diarios una vez validada por los expertos.

Tabla 1

Ficha de análisis de piezas periodísticas

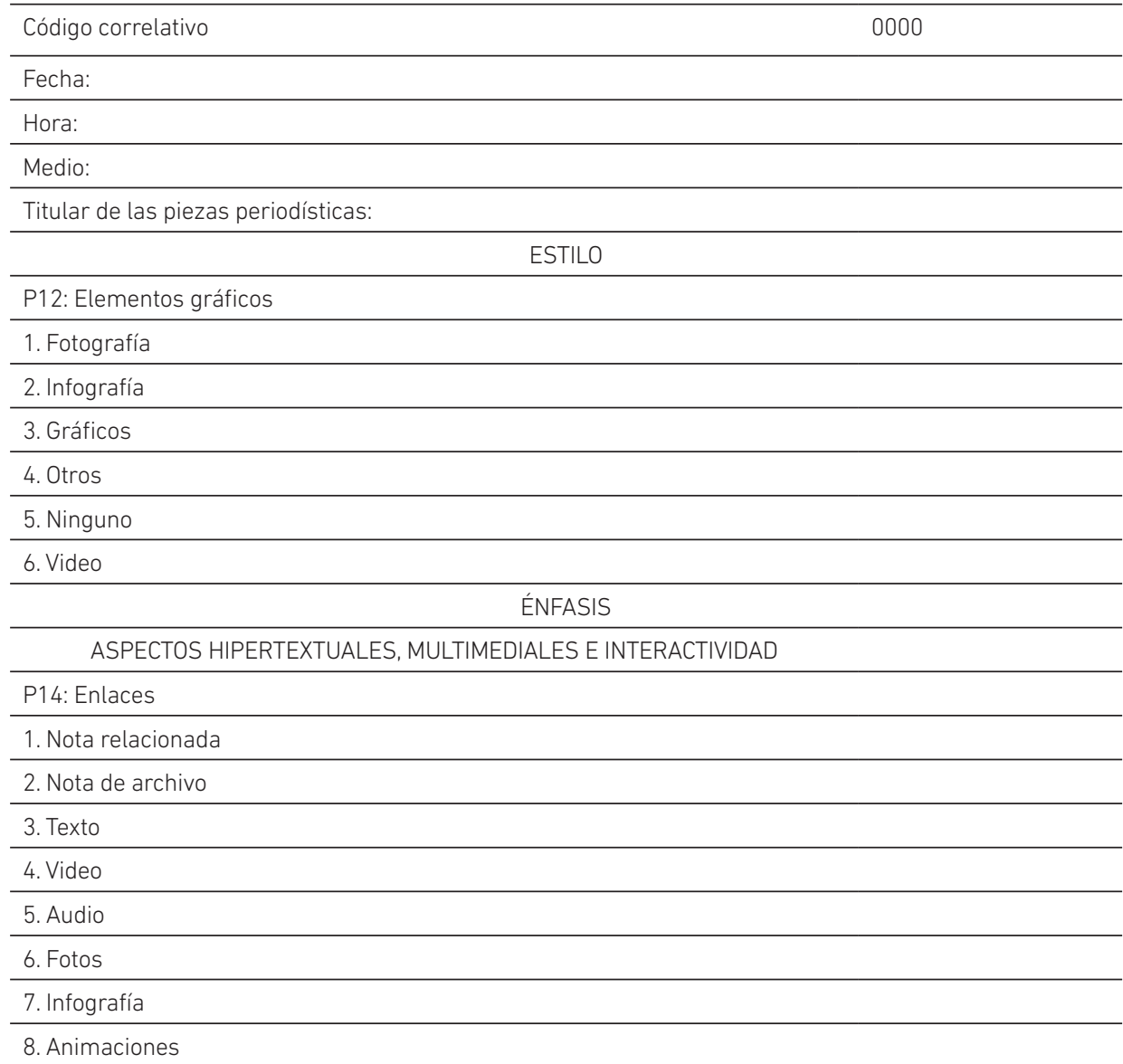


(continuación)

\begin{tabular}{l}
\hline 9. A Twitter / A Facebook \\
\hline 10. A instituciones gubernamentales \\
\hline 11. A instituciones privadas \\
\hline 12. Ninguno \\
\hline 13. Enlaces internos \\
\hline 14. Enlaces externos \\
\hline 15. Número de enlaces \\
\hline P15: Valoración del artículo (participación ciudadana) \\
\hline 1. Indignado \\
\hline 2. Triste \\
\hline 3. Indiferente \\
\hline 4. Sorprendido \\
\hline 5. Contento
\end{tabular}

Elaboración propia

Por las características del contexto de estudio, se optó por seleccionar un muestreo intencional:

i. Diario El Comercio del Ecuador: 1126 publicaciones

- 1 1. $^{\text {a }}$ semana del 16 al 24 de abril del 2016: 645 publicaciones

- 2. ${ }^{\text {a }}$ semana del 25 al 30 de abril del 2016: 246 publicaciones

- $\quad$ 3. ${ }^{a}$ semana del 1 al 8 de mayo del 2016: 132 publicaciones

- $\quad 4 .^{\text {a }}$ semana del 9 al 15 de mayo del 2016: 78 publicaciones

- 5. ${ }^{a}$ semana: 16 de mayo del 2016: 25 publicaciones

ii. Diario El País de España: 44 publicaciones

- $\quad$ 1. ${ }^{\text {a }}$ semana del 17 al 24 de abril del 2016: 33 publicaciones

- $\quad$ 2. ${ }^{\text {a }}$ semana del 25 al 30 de abril del 2016: 7 publicaciones

- $\quad$ 3. ${ }^{a}$ semana del 1 al 8 de mayo del 2016: 1 publicación

- $\quad 4 .{ }^{a}$ semana del 9 al 15 de mayo del 2016: 1 publicación

- $\quad$ 5. ${ }^{\text {a }}$ semana: 16 de mayo del 2016: 2 publicaciones

iii. Red social Facebook

Para la obtención de los datos a ser analizados, una vez determinado el periodo de estudio, se hizo de la siguiente manera. Se procedió a investigar en el portal web del diario El Comercio la posibilidad de acceder a las publicaciones referentes al terremoto del 
de abril durante el primer mes después de ocurrido el suceso. Se pudo evidenciar que el portal sí contaba con opción de buscador (https://goo.gl/AgV2XR), así como la selección de fecha de inicio y fin, hecho que facilitó acceder a las piezas periodísticas directamente utilizando las palabras \#Terremoto Ecuador. En ese muestreo se determinó un total de 1328 piezas periodísticas por ser analizadas.

Una vez obtenida la ficha de análisis, la muestra de investigación quedó en 1126. Algunas fueron eliminadas bajo el criterio del investigador, por cuanto eran publicaciones que no guardaban relación con el tema que estaba siendo investigado.

Con el diario El País de España se procedió de la misma forma. Se navegó en el portal web del diario y a través de la opción de búsqueda se pudo determinar utilizando las palabras \#Terremoto Ecuador. Con un banco de 1948 piezas periodísticas, se segmentó el rango de análisis del 16 de abril al 16 de mayo del 2016. Realizada esta selección, la muestra quedó en 44 noticias publicadas sobre el fenómeno natural ocurrido en el país sudamericano.

Concluida la selección de la muestra de los medios digitales tanto de Ecuador como de España, se trabajó en el levantamiento de la data de Facebook; con la ayuda de la empresa Viral Media de Guatemala se obtuvo el acceso directo al dashboard para visualizar los datos, además del levantamiento de un raw data a través de Excel. Con las dos fuentes de información se tabularon los datos, y la muestra de publicaciones de Facebook quedó en 1220 menciones. Realizado el análisis, la muestra estuvo formada por 1155 menciones; la cifra varió porque el investigador creyó necesario eliminar algunas publicaciones que no guardaban relación directa con el tema.

Se generó una matriz de datos en SPSS, versión 25 para Windows, paquete estadístico de amplio dominio que implementa variedad de módulos (Pérez-López, 2005). Luego de la transformación de datos cualitativos a cuantitativos (Tashakkori y Teddlie, 1998), para las variables nominales se calculó el estadístico chi-cuadrado de Pearson, con el cual se buscaba establecer una relación a un nivel de significancia óptimo o margen de error del $5 \%$ o 0,05. En el caso de las variables cuantitativas, se utilizó el análisis de varianza para comprobar la homogeneidad.

La triangulación que se emplea en esta investigación se sustenta en que "es un modelo metodológico ya existente: uno que responde a una tradición en las ciencias sociales que se distinguió por propugnar el uso de muchos métodos en torno a un mismo foco temático" (Samaja, 2018, p. 1). Así se enlazan el análisis de contenidos de las piezas comunicacionales, los criterios de expertos y la revisión de medios sociales.

\section{RESULTADOS}

En la tabla 1 se presentan los resultados obtenidos del análisis de los medios digitales. La morfología transmedia encontrada indica que dentro de los elementos gráficos 
es la fotografía el elemento primordial en la narración de la información; así, el diario El Comercio tuvo un total de 903 noticias con elementos gráficos (80,2\%), seguido del video, 133 imágenes (11,8 \%). En cambio, en el diario El País la fotografía se representó en 29 piezas periodísticas (65,9\%) y el video en 14 archivos (31,8 \%). Por otro lado, se pudo determinar que en el diario El Comercio los enlaces dentro de la información que predominaron fueron las notas relacionadas, 353 (47,3\%), seguidas de las fotos con 119 imágenes (15,9\%). Y con una representación significativa también están los enlaces a las redes sociales como Twitter y Facebook, con 112 (15\%). En tanto que el diario El País tuvo una representación significativa únicamente en los textos dentro de sus piezas periodísticas. Con relación a la cantidad de enlaces tanto internos como externos encontrados en los dos medios analizados, se puede indicar que el diario El Comercio contó con 1011 enlaces internos (72,4\%). De esta forma, el medio mantiene a sus lectores enganchados en las noticias relacionadas dentro de sus mismas webs. Por su parte, el diario El País contó con 182 enlaces internos (96,8 \%).

\section{Tabla 2}

Morfología transmedia

\begin{tabular}{|c|c|c|c|c|c|}
\hline & & \multicolumn{2}{|c|}{ El Comercio } & \multicolumn{2}{|c|}{ El País } \\
\hline & & $f$ & $\begin{array}{l}\text { Porcentaje } \\
\text { válido }\end{array}$ & $f$ & $\begin{array}{l}\text { Porcentaje } \\
\text { válido }\end{array}$ \\
\hline \multirow{7}{*}{$\begin{array}{l}\text { Elementos } \\
\text { gráficos dentro } \\
\text { de las piezas } \\
\text { periodísticas }\end{array}$} & Fotografía & 903 & 80,2 & 29 & 65,9 \\
\hline & Infografía & 6 & 0,5 & & \\
\hline & Gráficos & 2 & 0,2 & & \\
\hline & Otros & 4 & 0,4 & & \\
\hline & Ninguno & 78 & 6,9 & 1 & 2,3 \\
\hline & Video & 133 & 11,8 & 14 & 31,8 \\
\hline & Total & 1126 & 100,0 & 44 & 100,0 \\
\hline \multirow{10}{*}{$\begin{array}{l}\text { Tipo de enlace } \\
\text { dentro de } \\
\text { las piezas } \\
\text { periodísticas }\end{array}$} & Nota relacionada & 353 & 47,3 & & \\
\hline & Texto & 92 & 12,3 & 37 & 78,7 \\
\hline & Video & 47 & 6,3 & 1 & 2,1 \\
\hline & Audio & 1 & 0,1 & & \\
\hline & Fotos & 119 & 15,9 & 3 & 6,4 \\
\hline & Infografía & 6 & 0,8 & 3 & 6,4 \\
\hline & Animaciones & 15 & 2,0 & & \\
\hline & A Twitter/Facebook & 112 & 15,0 & 3 & 6,4 \\
\hline & A instituciones privadas & 2 & 0,3 & & \\
\hline & Total & 747 & 100,0 & 47 & 100,0 \\
\hline
\end{tabular}




\begin{tabular}{llrrrr} 
(continuación) & & & & \\
\hline Cantidad de & Enlaces internos & 1011 & 72,4 & 182 & 96,8 \\
enlaces dentro & Enlaces externos & 385 & 27,6 & 6 & 3,2 \\
de las piezas & Total & 1396 & 100,0 & 188 & 100,0 \\
periodísticas & & &
\end{tabular}

\section{Elaboración propia}

En la tabla 3 se condensa la cantidad de reacciones que tuvieron los internautas al momento de leer las piezas periodísticas del diario en la versión en línea. La categoría que más representación tuvo fue la valoración de contento: 15513 (35,5\%), esto demuestra que las personas que leían se sentían satisfechas frente a la atención y respuesta que se estaba dando por la magnitud del terremoto. En segundo lugar, existe un porcentaje representativo que demuestra su tristeza por lo acontecido: 15366 (35,1 \%). En tanto que la indignación estuvo representada por 9428 lectores $(21,6 \%)$ que sentían cierta indignación por el actuar de la comunidad, autoridades y ciudadanía ante los estragos del terremoto. Con una representación inferior al $6 \%$ se encuentran quienes reaccionan de manera sorprendida: 2329 (5,3\%), y de manera indiferente: 1087 (2,5\%).

Tabla 3

Valoración de las piezas periodísticas del diario El Comercio

\begin{tabular}{llcc}
\hline & Frecuencia & Porcentaje válido \\
\hline Válidos & Indignado & 9428 & 21,6 \\
& Triste & 15366 & 35,1 \\
& Indiferente & 1087 & 2,5 \\
& Sorprendido & 2329 & 5,3 \\
Contento & 15513 & 35,5 \\
& Total & 43723 & 100,0 \\
\hline
\end{tabular}

Elaboración propia

El diario El País de España únicamente permite a los lectores realizar comentarios en las piezas periodísticas, mas no tiene un apartado donde se dé una valoración diferente por parte del lector, la cual puede ser triste, contento, indiferente o sorprendido. El total de comentarios realizados en la muestra analizada fueron de 295 , lo que representa el $100 \%$.

Con relación al tipo de recurso periodístico utilizado dentro de las piezas del diario El Comercio de Ecuador (véase la tabla 4), el género informativo, con 932 piezas $(82,8 \%)$, es el predominante. El género gráfico con 71 (6,3\%) y el reportaje con 57 piezas $(5,1 \%)$ tienen un porcentaje inferior en la difusión de notas. En cuanto al tipo de 
género utilizado por el diario El País de España, el género informativo con 37 piezas $(84,1 \%)$ es el predominante.

La estructura de las piezas periodísticas muestra que la nota interpretativa, con $983(87,3 \%)$, representa el porcentaje más alto. Las piezas periodísticas restantes se reparten la valoración.

Tabla 4

Géneros y estructura

\begin{tabular}{|c|c|c|c|c|c|}
\hline & & \multicolumn{2}{|c|}{ El Comercio } & \multicolumn{2}{|c|}{ El País } \\
\hline & & $f$ & $\begin{array}{l}\text { Porcentaje } \\
\text { válido }\end{array}$ & $\begin{array}{l}\text { Porcentaje } \\
\quad \text { válido }\end{array}$ & $f$ \\
\hline \multirow{9}{*}{$\begin{array}{l}\text { Tipo de género más } \\
\text { utilizado por diario }\end{array}$} & Informativo & 932 & 82,8 & 37 & 84,1 \\
\hline & Crónica & 7 & 0,6 & & \\
\hline & Entrevista & 26 & 2,3 & 1 & 2,3 \\
\hline & Reportaje & 57 & 5,1 & & \\
\hline & $\begin{array}{l}\text { Género de opinión, } \\
\text { columna editorial }\end{array}$ & 30 & 2,6 & & \\
\hline & Artículo firmado & 1 & 0,1 & & \\
\hline & Género gráfico & 71 & 6,3 & 6 & 13,6 \\
\hline & Otros & 2 & 0,2 & & \\
\hline & Total & 1126 & 100,0 & 44 & 100,0 \\
\hline \multirow{7}{*}{$\begin{array}{l}\text { Estructura de las } \\
\text { piezas periodísticas }\end{array}$} & Pirámide invertida & 3 & 0,3 & & \\
\hline & Nota interpretativa & 983 & 87,3 & 38 & 86,4 \\
\hline & Opinión & 28 & 2,5 & & \\
\hline & Cronológica & 1 & 0,1 & & \\
\hline & Entrevista & 15 & 1,3 & 1 & 2,3 \\
\hline & Otros & 96 & 8,5 & 5 & 11,4 \\
\hline & Total & 1126 & 100,0 & 44 & 100,0 \\
\hline
\end{tabular}

\section{Elaboración propia}

La muestra analizada de la plataforma de Facebook del 16 de abril, a las 19:00 horas, al 16 de mayo, a las 23:59 horas, fue de 1155 publicaciones públicas que los usuarios compartieron o difundieron luego de ocurrido el terremoto. Un día después del terremoto se publicaron 226 notas (19,6\%), en tanto que el mismo día de ocurrido el evento natural hubo 127 publicaciones (11\%). En los días siguientes, a partir del 18 al 24 de abril, la cantidad de publicaciones fue variando en porcentajes: el 18 de abril (7,9\%), 91 piezas, y el 24 de abril se registró un total de 18 piezas (1,6\%). Debido a la cantidad de réplicas (889) que se produjeron desde el 16 hasta el 25 de abril, ese día se contabilizaron 
73 publicaciones (6,3\%). A partir del 26 de abril hasta el 16 de mayo la cantidad de publicaciones fueron de $14(1,2 \%)$ a $50(4,3 \%)$ por día.

La interacción por parte de los usuarios en las publicaciones de la red social Facebook fue de 2777016 (70,2 \%) reacciones. La participación de los internautas a través de las reacciones, sean estas positivas o negativas de acuerdo con las posibilidades que brinda la plataforma, llegó más allá de los dos millones y medio de reacciones. Comentarios: 134215 (3,4\%), compartidos 1046688 (26,4\%).

La publicación con la mayor cantidad de reacciones (90 119) fue de la cuenta "Tercer Cielo", que compartió un video el 22 de abril que capta el instante en que ocurrió el terremoto. El video fue grabado en una iglesia evangélica donde se ve a la asamblea que sigue alabando a Dios mientras sucede el movimiento. La publicación con mayores comentarios (4406) es del 17 de abril, realizada por el futbolista Ronaldinho Gaúcho, la cual tuvo gran aceptación por parte de los usuarios de la plataforma social, quienes reaccionaron positivamente ante el mensaje publicado. La publicación más compartida (84 775) es una canción realizada por un joven migrante desde Italia.

La tabla 5 presenta el análisis del nivel de reacción que tuvieron los usuarios frente a su posición (positiva, negativa o neutra) de las piezas periodísticas que se publicaron en el primer mes después del terremoto. Por género de usuario, 665 publicaciones $(57,6 \%)$ corresponden a fanpages pertenecientes a instituciones públicas, privadas, ONG o páginas de personas naturales que poseen una fanpage personal. En tanto, 318 publicaciones (27,5\%) fueron realizadas por hombres, y $172(14,9 \%)$ fueron realizadas por mujeres. Si consideramos solo estos dos indicadores, se puede observar que los hombres fueron quienes estuvieron más pendientes y tuvieron más participación.

De acuerdo con el tipo de publicaciones que se detectaron a través de la red social Facebook, se puede determinar que el link (enlace) tuvo 365 publicaciones (31,6\%), la imagen se compartió unas 328 veces $(28,4 \%)$, en tanto que el video se compartió un total de 260 veces (22,5\%). Mensajes a través de texto se publicaron en 122 momentos $(10,6 \%)$, los mensajes de ánimo se compartieron 51 veces $(4,4 \%)$, los llamados a la acción se registraron 21 veces $(2,2 \%)$, los consejos $6(0,5 \%)$ y los concursos 2 veces $(0,2 \%)$. Cada una de estas formas de publicaciones se dio durante los primeros 30 días luego del terremoto. 
Tabla 5

Características de publicaciones en Facebook

\begin{tabular}{llrr}
\hline & & Frecuencia & Porcentaje válido \\
\hline \multirow{3}{*}{ Sentimiento de los usuarios } & Positivo & 763 & 66,1 \\
& Negativo & 324 & 28,1 \\
& Neutro & 68 & 5,9 \\
& Total & 1155 & 100,0 \\
\hline \multirow{3}{*}{ Género de los usuarios } & Hombre & 318 & 27,5 \\
& Mujer & 172 & 14,9 \\
& Fanpage & 665 & 57,6 \\
& Total & 1155 & 100,0 \\
\hline \multirow{3}{*}{ Tipo de publicaciones } & Texto & 122 & 10,6 \\
& Imagen & 328 & 28,4 \\
& Mensaje de ánimo & 51 & 4,4 \\
& Link & 365 & 31,6 \\
& Video & 260 & 22,5 \\
& Consejo & 6 & 0,5 \\
& Llamado a la acción & 21 & 1,8 \\
& Concurso & 2 & 0,2 \\
& Total & 1155 & 100,0 \\
\hline
\end{tabular}

Elaboración propia

Los enlaces internos tuvieron mayor representatividad en el género informativo con ( $t[932]=82,80, p<.05)$, en la crónica con $(t[7]=0,60, p<.05)$, en la entrevista con $(t[26]=2,30, p<.05)$, en el reportaje con $(t[46]=4,10, p<.05)$; en tanto que los enlaces externos con una mínima representación estuvieron presentes en el género de reportaje con $(\mathrm{t}[11]=1,0, \mathrm{p}<.05)$; en el género de opinión, columna editorial, con $(\mathrm{t}[30]=2,70$, $\mathrm{p}<.05)$; $y$ en el artículo firmado con $(\mathrm{t}[1]=0,10, \mathrm{p}<.05)$. La presencia de más enlaces internos desde las piezas periodísticas busca potenciar la misma página del diario, dado que estos enlaces llevan a contenido relacionado con la información que se visualiza; es decir, el propósito es mantener la fidelidad del lector hacia el diario. En cambio, los enlaces externos llevan la información a otros sitios fuera del diario, para complementar la información o los datos desde otros tipos de fuentes.

La mayor coyuntura de la información se dio en las primeras 48 horas después del terremoto. La producción de la información se desarrolló en la sección "Actualidad" del diario El Comercio. Así, el 16 de abril, después de las 18:58 hasta las 23:59 horas, difundió 6 piezas periodísticas $(\mathrm{t}[6]=0,50, \mathrm{p}<.05)$. 
El 17 de abril, en esa misma sección, se publicaron 110 informaciones $(\mathrm{t}[110]=9,80$, $\mathrm{p}<.05)$ en la versión digital del medio de comunicación; el lunes 18 de abril se difundió $(\mathrm{t}[111]=9,90, \mathrm{p}<.05)$, el martes 19 de abril se publicó $(\mathrm{t}[95]=8,40, \mathrm{p}<.05)$, el miércoles 20 de abril ( $t[87]=7,70, p<.05)$, el jueves 21 de abril $(t[65)=5,80, p<.05)$, el viernes 22 de abril (t[78] $=6,90, p<.05)$, en tanto que el sábado 23 de abril, a ocho días del terremoto, se difundieron 60 piezas periodísticas $(t[60]=5,30, p<.05)$.

Del 24 al 28 de abril, la información en la sección "Actualidad" tuvo una producción de entre $(t[33]=2,90, p<.05)$ y $(t[15]=1,30, p<.05)$. El 28 de abril la información formó parte de la sección “Tendencias" con una difusión de ( $\mathrm{t}[24]=2,10, \mathrm{p}<.05)$, al 2 de mayo con $(t[7]=0,60, p<.05)$. Transcurridas las dos primeras semanas, la información se fue diversificando en las diferentes secciones del diario, pasando por la sección "Opinión" $(\mathrm{t}[12]=1,10, \mathrm{p}<.05)$ el 4 de mayo; el video con una mayor difusión se propaló el lunes 9 de mayo $(\mathrm{t}[21]=1,90, \mathrm{p}<.05)$ y las "Fotogalerías" el 15 de mayo con $(\mathrm{t}[6]=1,40, \mathrm{p}<.05)$.

Al analizar los elementos gráficos en las piezas periodísticas de acuerdo con el tipo de género, se determina que la fotografía tuvo mayor presencia en el tipo de género informativo, con un total de $(\mathrm{t}[29]=65,90, \mathrm{p}<.05)$ piezas periodísticas, al igual que el video dentro del mismo género con $(t[7]=15,90, p<.05)$; el video también estuvo presente en los géneros gráficos con $(t[6]=13,60, p<.05)$ y en la entrevista con $(t[1]=2,30, p<.05)$.

\section{DISCUSIÓN}

La necesidad de educar e informar a los ciudadanos en el ámbito de la prevención y cuidado ante los desastres naturales, la forma de transmitir esa información entre la población y el tratamiento que le dan los medios digitales de comunicación justifica el análisis e implementación de la presente investigación, por lo que el estudio sobre el terremoto en Ecuador representa una alternativa a la participación de la población en conocer cómo vivió y cómo se informó desde las diferentes plataformas de comunicación. En el caso de la red social Facebook, el fin que se persigue es averiguar la utilidad de este tipo de plataformas digitales en casos de emergencia. Por esa razón, se pretende analizar pormenorizadamente la situación a fin de aprender de la experiencia y proponer mejoras para el futuro.

Para responder cuál es la importancia que le dan los medios digitales a la cobertura de un fenómeno natural en un contexto nacional e internacional, debe señalarse que el tratamiento de la información de un fenómeno natural llega a tener una mayor inmediatez por el uso de las plataformas digitales. La aparición de estas nuevas formas de comunicación ha permitido que las sociedades se pronuncien (Enríquez, 2016). La mayor cantidad de información acerca del terremoto se difundió en las primeras ocho horas después de ocurrido; esta inmediatez se mantuvo con un nivel aceptable durante la primera semana. 
El análisis arrojó que transcurrido el octavo día la difusión bajó con relación a los primeros instantes. Muy bien señalan Arroyo et al. (2009) que la información se vuelve el elemento más preciado e importante, ya que todos buscan la manera de informar y así ganar o perder visibilidad. Esto coincide con lo que manifiesta Lozano (2009): en momentos de un desastre natural o un evento de consecuencias globales, es este el que marca las rutinas periodísticas en los medios.

Tras el análisis de las piezas informativas, El Comercio tuvo una mayor presencia durante la primera semana (del 16 al 24 de abril) con 645 piezas informativas; esto se debió a las consecuencias e impacto que provocó el terremoto, dejando destrucción y pérdidas para el país y la población. En el mismo periodo El País llegó a publicar 33 piezas informativas.

Con relación al área temática de la cobertura del terremoto hecha por los medios, El Comercio presentó las piezas informativas que incluyeron temáticas relacionadas de forma directa con el desastre natural y epidemias, lo que equivale al $72,9 \%$, además de historias de interés humano, salud y bienestar, deportes y en una cobertura inferior destacamos las temáticas de economía, trabajo y gremios, así como los eventos culturales. En cambio, El País centró su atención en la temática de desastres naturales y epidemias en cerca del $96 \%$ de sus piezas informativas, en tanto que en una minoría se habló sobre economía y el trabajo y gremios.

La web es la principal aliada de los medios digitales en los últimos años y el diario $E l$ Comercio ha sabido aprovechar las potencialidades que las nuevas tecnologías brindan. Así se mantiene como uno de los diarios con mejor plataforma en su versión digital entre los medios de Ecuador.

Durante la cobertura del terremoto la presencia del elemento gráfico como la fotografía fue la que primó en cada pieza periodística del género informativo. Contó con cerca del 80,2 \% y se llegó a publicar 903 imágenes solo en el diario El Comercio del total de 1126 piezas periodísticas. Sobre las infografías, se utilizaron 6, es decir, un 0,5\%. En el diario El País la fotografía fue utilizada en un 65,9 \%, con un total de 29 imágenes publicadas entre las 44 piezas periodísticas que cubrió el medio internacional sobre el terremoto del 16 de abril.

El prosumidor actual es una persona que está constantemente interactuando a través de los dispositivos tecnológicos, generando y consumiendo información. Las nuevas generaciones tienden a observar las cosas de forma diferente, en distintos medios y con diferentes modalidades de consumo (en vivo, streaming, descargas, etcétera) (Scolari, 2013).

En un momento de caos tras un hecho como un terremoto, las personas buscan estar informadas y conocer los pormenores que están sucediendo al instante, esto con el 
afán de saber sobre la situación de personas allegadas, familiares o conocidos; además de informarse cómo se desarrolla la cobertura desde los medios y ahora también desde los prosumidores a través de las plataformas digitales o redes sociales. La red social Facebook fue fundamental en el momento de informar sobre el terremoto. A los pocos minutos de sucedido el desastre, empezó a salir información a través de esta red. Vanessa Castro Jiménez, de la ciudad de Guayaquil, fue una de las primeras en informar a las 19:00 horas, a través de Facebook, el terremoto que acababa de suceder y que se sintió en casi todo el país. A decir de Mancinas y Nogales (2011), las redes sociales han facilitado al usuario el contacto personal y la difusión de información desde sus perfiles con contenido hipertextual tanto en video como en texto.

El tipo de publicación más utilizado en las primeras horas fue el texto con un 10,6\%. En tanto que a lo largo del mes de análisis se pudo comprobar que el tipo de contenido más difundido fueron los links con un 31,6\%. Conforme se iban restableciendo los servicios de energía eléctrica en las ciudades como Esmeraldas, Portoviejo, Bahía de Caráquez, Guayaquil y Santo Domingo, los usuarios compartían otros recursos como los mensajes de ánimo (4,4\%), las imágenes (28,4\%), el video (22,5\%), los consejos $(0,5 \%)$ y el llamado a la acción (1,8 \%). Esto permitió que la población conozca desde otro recurso digital, al instante, lo que estaba sucediendo en los diferentes sitios donde más daño había dejado el movimiento telúrico.

De acuerdo con la información obtenida desde Facebook, la interacción entre los usuarios se manifestó en un gran alcance a través de los comentarios, los compartidos y las interacciones.

\section{CONCLUSIONES}

La narrativa periodística se ha visto fortalecida por la variedad de recursos que permiten retratar una historia en diversos contextos. En el caso de los desastres naturales, tal como se muestra en esta investigación, los recursos más utilizados siguen siendo la fotografía y el video. Sin embargo, hay que destacar el uso de otros recursos en el medio de comunicación ecuatoriano, como la infografía, los gráficos, las animaciones y los audios, que aportan elementos adicionales a la forma de contar un hecho. Mientras que en El País las historias siguen siendo acompañadas de fotografía y video.

A esto se suma el uso de fuentes que permiten contar la historia y a la vez aportar credibilidad a la investigación periodística. En el diario El Comercio, las principales fuentes fueron gubernamentales, lo que evidencia que en estos casos la información proviene de fuentes relacionadas con el Gobierno antes que de la búsqueda de información propia del periodista, lo que deja entrever la falta de iniciativa y capacitación de este último sobre cómo actuar en este tipo de eventos. En El País las piezas periodísticas provienen de agencias. 
Sin embargo, existe un interés de los medios estudiados de contextualizar los hechos; esto se observa en el uso de enlaces internos y externos, que permiten al usuario contar con una visión más amplia de las piezas periodísticas. Los enlaces internos son los que predominan, lo que se debe principalmente a que el medio busca incrementar el número de visitas y evitar que el usuario salga de la página web, y así mejorar el posicionamiento SEO (search engine optimization, por sus siglas en inglés) independientemente de si el contenido es o no de calidad.

Al analizar la interacción de los prosumidores a través de las publicaciones que realizaron sobre el terremoto entre abril y mayo del 2016 mediante Facebook, se señala lo siguiente:

- En un momento de caos tras un hecho como un terremoto, las personas buscan estar informadas y conocer los pormenores de lo que está sucediendo al instante, esto con el afán de saber sobre la situación de personas allegadas, familiares o conocidos; además de informarse sobre cómo se desarrolla la cobertura desde los medios y ahora desde las personas a través de las plataformas digitales o redes sociales. En ese sentido, la red social Facebook demostró ser más utilizada en un momento de crisis, incluso logró mantener un sentido de filialidad, los habitantes conservan los imaginarios y las características asociadas por ellos a su pueblo (Quezada, 2020).

- Las nuevas plataformas sociales han permitido al comunicador el poder tener una herramienta más a su alcance para informar; sin embargo, aún se percibe un distanciamiento entre periodistas y cibernautas, brecha que debería reducirse. En la investigación se concluye que las redes sociales como Facebook, aunque no son siempre confiables en situaciones de crisis, aportan con información de interés para el comunicador o el medio contribuyendo a salvar vidas, dada la ubicación e información que emitían las personas a través de esta plataforma, como sucedió en Ecuador.

\section{REFERENCIAS}

Abad-Sojos, A., Martínez-Cornejo, I., Obregón-Jiménez, K., Palacios-Segarra, D., AnaluisaLema, I., y Flores-Enríquez, J. (2018). Conocimientos, actitudes y prácticas sobre catástrofes naturales en estudiantes de Medicina de la Universidad Central del Ecuador, 2017. CIMEL, 23(1), 41-46. https://doi.org/10.23961/cimel.v23i1.1068

Alcázar, J. del. (2020). Estadísticas Facebook Ecuador. Mentinno Innovación \& Lifetime Value Partners. https://bit.ly/2FNodbX

Arroyo, S., Rodríguez, M., y Pérez, R. (Eds.). (2009). Gestión de la información y comunicación en emergencias y desastres. Guía para equipos de respuesta. Organización 
Panamericana de la Salud. https://www.paho.org/chi/dmdocuments/Gestion DelnformComunica_LowRes\%20Dic\%2009.pdf

Ballesteros, B. (2014). Reflexión sobre la teoría de la sociedad del riesgo. Temas Sociales, 35, 203-215. https://bit.ly/2Xzbr9z

Crovi, D., y Lozano, C. (2010). La faena de lo incierto. Incertidumbre y medios de comunicación. Universidad Nacional Autónoma de México; Sitesa.

elDiario.es, el cuarto periódico digital más leído y el que más crece. (17 de septiembre del 2020). El Diario. https://www.eldiario.es/redaccion/eldiario-cuarto-periodicodigital-leido-crece_132_6226205.html

Enríquez, R. (2016). Comprensión de la utilización de las redes sociales en las narrativas transmedia en desastres naturales. Caso: terremoto de Ecuador abril 2016 [Tesis de grado, Universidad Central del Ecuador]. https://bit.ly/3glihyN

Escobar, M. (2003). Reseña de "La sociedad del riesgo global" de Ulrich Bech. Reis. Revista Española de Investigaciones Sociológicas, 101, 279-283. https://bit.ly/3xRypoF

Francescutti, L., Tucho, F., e Îñigo, A. (2013). El medio ambiente en la televisión española: análisis de un año de informativos. Estudios sobre el Mensaje Periodístico, 19(2), 683-701.

Islas, J. (2008). El prosumidor. El actor comunicativo de la sociedad de la ubicuidad. Palabra Clave, 11(1), 29-39. https://www.redalyc.org/articulo.oa?id=64911103

Jenkins, H. (21 de marzo del 2007). Transmedia Storytelling 101. Confessions of an Aca-Fan. http://henryjenkins.org/2007/03/transmedia_storytelling_101.html

Jenkins, H. (12 de diciembre del 2009). The Revenge of the Origami Unicorn: Seven Principles of Transmedia. Confessions of an Aca-Fan. http://henryjenkins.org/ blog/2009/12/the_revenge_of_the_origami_uni.html

Lozano, C. (2009). El medio ambiente como una referencia dominante en la construcción social del acontecer catastrófico. En J. Carabaza (Ed.), Comunicación y medio ambiente. Reflexiones, análisis y propuestas (pp. 132-159). Tecnológico de Monterrey.

Lozano, C., y Amaral, F. (2018). Coberturas informativas de la prevención y del acontecer de catástrofes a través de los "manuales institucionales" dirigidos a los periodistas. Estudios Rurales, 8, 6-17.

Lozano, C., Amaral, M., y Puertas, E. (2020). Los relatos periodísticos de riesgos y catástrofes en las televisiones de España. Revista Mexicana de Investigación Educativa, 25(87), 1183-1209. 
Lozano, C., y Toussaint, F. (2019). Las coberturas mediáticas del terremoto de México del 19 de septiembre del 2017. En M. Amaral y C. Lozano (Eds.), Periodismo y desastres. Múltiples miradas (pp. 121-141). Universitat Autónoma de Barcelona, Institut de la Comunicació.

Mancinas, R., y Nogales, A. (2011). Redes sociales: generalidades y aplicaciones. En R. Reig y C. Langa-Nuño (Eds.), La comunicación en Andalucía: historia, estructura y nuevas tecnologías (pp. 667-689). https://bit.ly/37fgu00

Manjón, N. H. (2020). 10 años del terremoto de Haití: la importancia de la labor enfermera en catástrofes naturales. Metas de Enfermería, 23(6), 36-37.

Marcelo, C., y Marcelo, P. (2021). Educational Influencers on Twitter. Analysis of Hashtags and Relationship Structure. Comunicar, 68, 73-83. https://doi.org/10.3916/ C68-2021-06

Mendoza-Michilot, M. (2017). El rostro de los diarios digitales en el Perú. Universidad de Lima, Fondo Editorial.

Mora, V. (2014). Acercamiento al problema terminológico de la narrativa transmedia. Caracteres, 3(1), 11-41. https://bit.ly/34aOvhg

Pellegrini, S., Puente, S., y Grassau, D. (2015). La calidad periodística en caso de desastres naturales: cobertura televisiva de un terremoto en Chile. Estudios sobre el Mensaje Periodístico, 21, 249-267. https://doi.org/10.5209/rev

Pellegrini, S., Puente, S., Porath, W., Mujica, C., y Grassau, D. (2011). Valor agregado periodístico: la apuesta por la calidad de las noticias. Ediciones UC.x

Pérez-López, C. (2005). Técnicas estadísticas con SPSS 12: aplicaciones al análisis de datos. Pearson.

Quezada, M. (2020). Chanco: imaginario representado, antes y después del terremoto de 2010. F@ro: Revista Teórica del Departamento de Ciencias de la Comunicación y de la Información, 1(31), 75-93.

Renó, D. (2013). Narrativa transmedia y la "des-gobernabilidad" periodística. Comunicação y Sociedade, 34(2), 141-161. http://hdl.handle.net/11449/135243

Renó, D., Campalans, C., Ruiz, S., y Gosciola, V. (2014). Periodismo transmedia: miradas múltiples. Editorial UOC.

Rivera, J. (2020). Periodismo de datos en Ecuador. Análisis de casos: El Comercio y Plan V. Chasqui. Revista Latinoamericana de Comunicación, 1(145), 327-342. https://doi. org/10.16921/chasqui.v1i145.3813 
Samaja, J. (2018). La triangulación metodológica (pasos para una comprensión dialéctica de la combinación de métodos). Revista Cubana de Salud Pública, 44(2), 431-443.

Scolari, C. A. (10 de noviembre del 2011). Narrativas transmediáticas y adaptaciones: el caso Tintin. Hipermediaciones. https://bit.ly/3nwYiVT

Scolari, C. A. (2013). Narrativas transmedia: cuando todos los medios cuentan. Deusto.

Scolari, C. A., Jiménez, M., y Guerrero, M. (2012). Narrativas transmediáticas en España, cuatro ficciones en busca de un destino "cross-media". Comunicación y Sociedad, XXV(1), 137-163. https://bit.ly/3qON4i1

Souza-Mayerholz, M., y Martínez-Ravanal, V. (2011). La intervención de la televisión en el terremoto chileno. Comunicar, 36, 69-76. https://doi.org/10.3916/C36-2011-02-07

Suing, A. (2018). La información en la televisión del terremoto ocurrido en Ecuador en abril de 2016. Razón y Palabra, 22(1-100), 374-390. https://goo.gl/UUv4dy

Tashakkori, A., y Teddlie, C. (1998). Mixed Methodology: Combining Qualitative and Quantitative Approaches. Sage.

Teso, G., Fernández, R., Gaitán, J., Lozano, C., y Piñuel, J. (2018). Comunicaciónparalasostenibilidad,elcambioclimáticoenlosmedios.FundaciónAlternativas. https://www.fundacionalternativas.org/sostenibilidad/documentos/documen tos-de-trabajo/

Toala, D., y Camino, B. (2017). Reacción de los nodos de una red social luego del terremoto en Ecuador. Conference Proceedings UTMACH, 1(1), 1038-1045. https://goo.gl/ hVe55q

Toffler, A. (1981). La tercera ola. Edivisión.

Vidal, F. (1994). Los terremotos y sus causas. En F. Vidal y A. Posadas (Coords.), Los terremotos y sus causas. El estudio de los terremotos en Almería (pp. 17-38). Instituto de Estudios Almerienses. https://goo.gl/XL2PMb 